\title{
Genetic Approaches to Understanding Psychiatric Disease
}

\author{
Jacob J. Michaelson ${ }^{1,2,3,4,5,6,7}$
}

Published online: 12 June 2017

(C) The American Society for Experimental NeuroTherapeutics, Inc. 2017

\begin{abstract}
Human genetic studies have been the driving force in bringing to light the underlying biology of psychiatric conditions. As these studies fill in the gaps in our knowledge of the mechanisms at play, we will be better equipped to design therapies in rational and targeted ways, or repurpose existing therapies in previously unanticipated ways. This review is intended for those unfamiliar with psychiatric genetics as a field and provides a primer on different modes of genetic variation, the technologies currently used to probe them, and concepts that provide context for interpreting the gene-phenotype relationship. Like other subfields in human genetics, psychiatric genetics is moving from microarray technology to sequencing-based approaches as barriers of cost and expertise are removed, and the ramifications of this transition are discussed here. A summary is then given of recent genetic
\end{abstract}

Electronic supplementary material The online version of this article (doi:10.1007/s13311-017-0551-x) contains supplementary material, which is available to authorized users.

Jacob J. Michaelson

jacob-michaelson@uiowa.edu

1 Department of Psychiatry, University of Iowa Carver College of Medicine, Iowa City, IA, USA

2 Department of Biomedical Engineering, University of Iowa College of Engineering, Iowa City, IA, USA

3 Department of Communication Sciences and Disorders, University of Iowa College of Liberal Arts and Sciences, Iowa City, IA, USA

4 Iowa Institute of Human Genetics, University of Iowa, Iowa City, IA, USA

5 Genetics Cluster Initiative, University of Iowa, Iowa City, IA, USA

6 The DeLTA Center, University of Iowa, Iowa City, IA, USA

7 University of Iowa Informatics Initiative, University of Iowa, Iowa City, IA, USA discoveries in a number of neuropsychiatric conditions, with particular emphasis on neurodevelopmental conditions. The general impact of genetics on drug development has been to underscore the extensive etiological heterogeneity in seemingly cohesive diagnostic categories. Consequently, the path forward is not in therapies hoping to reach large swaths of patients sharing a clinically defined diagnosis, but rather in targeting patients belonging to specific "biotypes" defined through a combination of objective, quantifiable data, including genotype.

Key Words Psychiatric genetics · copy number variant · sequencing $\cdot$ microarrays $\cdot$ GWAS

\section{Introduction}

The familiality of psychiatric illness has long been appreciated, but only in the past decade or so have the tools and resources become available to probe its genetic determinants directly. This new era of genetics is particularly meaningful in psychiatry, where, unlike other medical fields, disorders have often been diagnosed and treated subjectively and in the absence of a clear biological framework. Furthermore, the historically unappreciated link between mental illness and biology has led to centuries of stigma for those suffering. By using genetics to frame mental illness as a biomedical phenomenon, there is hope that stigma can be alleviated.

Because many aspects of psychiatric illness are uniquely human and have no adequate animal or cellular model, human genetic research studies are particularly crucial for illuminating the underlying biology of these conditions. As these studies fill in the gaps in our knowledge, we will be better equipped to design therapies in a rational and targeted way. 
This review is intended for outsiders to the field of psychiatric genetics and perhaps even genetics in general. I begin by laying a foundation of basic aspects of genetic variation so that the most salient genetic findings from a number of major neurodevelopmental and neuropsychiatric conditions can be appreciated in their context in the latter half of the review. First, an overview of different kinds of genetic variation is given, followed by technologies currently used to probe them. General concepts that routinely come up in these genetic studies are then reviewed, and finally a brief synopsis of current trajectories of discovery in the major neurodevelopmental and neuropsychiatric conditions is given.

\section{Types of Genetic Variation}

Aneuploidy, the largest of the genetic variations (Fig. 1), is an abnormal chromosome count resulting from errors in chromosome segregation during cell division. Aneuploidy increases in the maternal germline with advancing maternal age [1]. Most aneuploidies that occur in the germline are embryonic lethal, but some result in viable individuals with developmental syndromes, the most well-studied examples being Down syndrome (trisomy 21) and Klinefelter syndrome (47, XXY), as well as Turner syndrome (monosomy X), Edward syndrome (trisomy 18), and Patau syndrome (trisomy 13). Exciting approaches that re-engineer X-inactivation mechanisms for potential treatment of some aneuploidies are currently under investigation $[2,3]$.

Fig. 1 Size distributions of classes of genetic variation, and the ability of microarray and sequencing technology to detect them. Solid circle $=$ routinely detectable; $(+)=$ detectable depending on platform, or with special protocols, or with limitations on size or coverage; $(-)=$ not detectable; $\mathrm{SNP}=$ single-nucleotide polymorphism; $\mathrm{SNV}=$ single nucleotide variant; indel $=$ insertion $/$ deletion; STR $=$ short tandem repeat; VNTR = variable number tandem repeat; $\mathrm{SV}=$ structural variant; $\mathrm{CNV}=$ copy number variant
Genomic structural variants (SVs) occur on a subchromosomal scale (Fig. 1) and include inversions and translocations (where there is no net loss of genetic material, such as the balanced translocation involving DISCl in schizophrenia (SZ) [4]), as well as deletions and duplications (where there is a net loss or gain, respectively, of genetic material). Deletions and duplications comprise a subclass of SVs called copy number variants (CNVs). SVs are sometimes arbitrarily defined as larger than $1 \mathrm{~kb} \mathrm{[5,6];} \mathrm{however,} \mathrm{in} \mathrm{actuality,} \mathrm{their}$ size distribution is continuous, with smaller variants being more numerous within an individual genome and larger variants being less numerous. Ascertainment of CNVs has played a crucial role in psychiatric genetics over the past decade, as it has helped to turn the spotlight from the common variants popularized by genome-wide association studies (GWAS) to rare variants of large effect [7]. CNVs are a normal form of human genetic variation [8,9], but neuropsychiatric populations show enrichment for de novo and rare, large CNVs [7, 10-16]. Genes that support the development and function of the brain tend to be larger than other genes, and so are more frequently affected by structural variation [17]. Furthermore, segmental duplications, which can act as a catalyst for SVs, are expanding in the primate and specifically the human lineage [18], with brain genes particularly affected [19]. Taken together, structural variation is an important mode of genetic variation in human evolution and disease in general, and in neuropsychiatric conditions in particular.

Short tandem repeats (STRs) and variable number tandem repeats (VNTRs), are smaller genetic variations (typically a few to hundreds of base pairs, and up to thousands of base

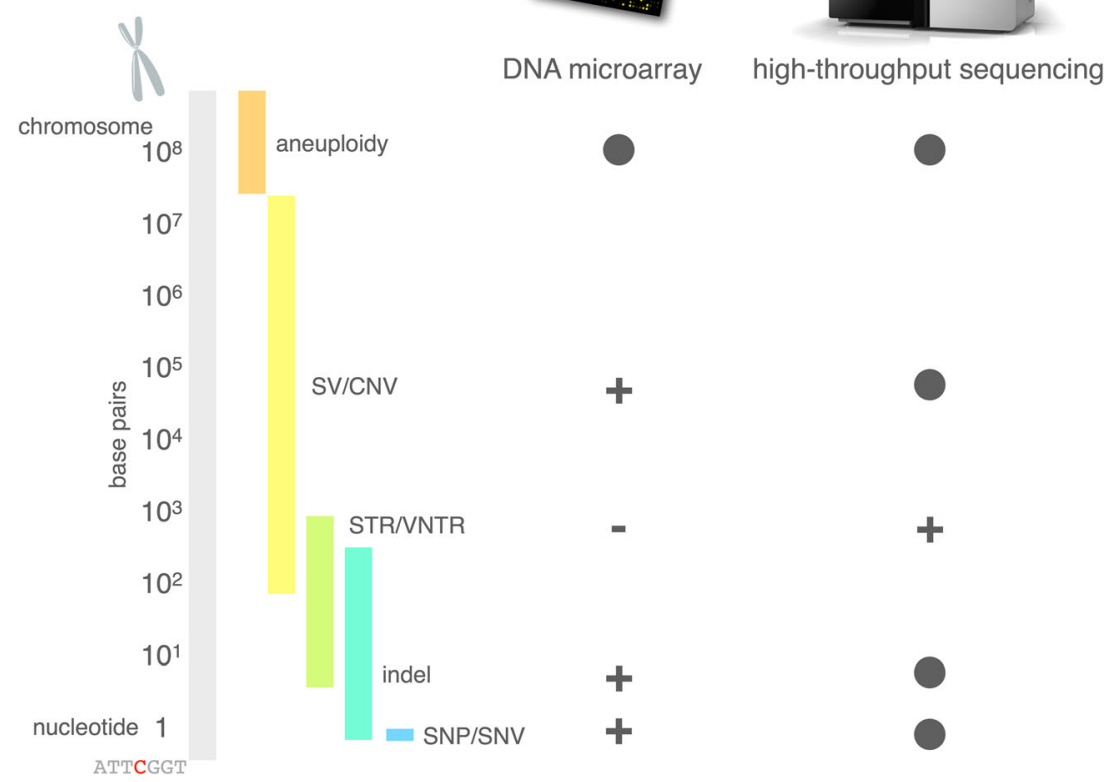

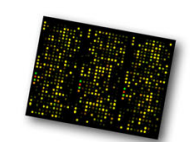

DNA microarray

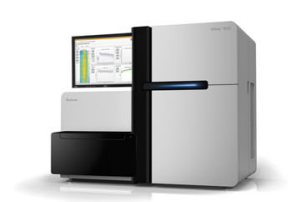

high-throughput sequencing 
pairs for VNTRs; see Fig. 1), consisting of a number of repeats of some core polynucleotide sequences (2-6 for STRs and 7100 for VNTRs) . STRs arise chiefly as a result of slippage of DNA replication machinery and have high mutation rates compared with other forms of genetic variation [20]. Wellstudied conditions with STRs as the causal factor include Huntington disease (HD) and Fragile X syndrome. In huntingtin (HTT), the gene that underlies HD, a CAG trinucleotide repeat encodes a polyglutamine tract in the corresponding huntingtin protein. If this STR expands past 35 repeats, the polyglutamine tract of the corresponding protein causes protein aggregation, which is pathogenic, and results in progressive neurodegeneration, chorea, psychiatric systems, and early death [21]. The CAG repeat is unstable and expansion between generations can lead to earlier onset of the disease, a phenomenon known as anticipation. In contrast to $\mathrm{HD}$, the STR that underlies Fragile X syndrome lies in a noncoding regulatory sequence, upstream of FMR1. If this CGG repeat expands past $\sim 200$ units, the promoter becomes hypermethylated and gene expression of FMR1 is shut down [22]. FMR1 encodes a vital regulatory protein that binds mRNAs, in particular those related to synaptic function, and loss of FMR1 results in mass dysregulation of protein expression and autism-like neurodevelopmental features. Genotyping STRs at a genome-wide scale using highthroughput sequencing technology is not routinely done because read lengths are not currently long enough to read through many STRs while still having enough flanking sequence to reliably map them. Consequently, while specific markers are used for forensics or diagnosing well-known diseases, relatively little is known about the role of STRs in disease at the genomic scale.

Indels (insertion/deletions) are polynucleotide expansions (insertion) or contractions (deletion) relative to the reference genome. Like SVs, the size distribution of indels is continuous, but generally variants ranging from 1 to 50 base pairs are considered indels (with larger indels becoming indistinguishable from small SVs; see Fig. 1) [23]. In protein-coding sequence, indels that are not multiples of 3 are under selective pressure because they would induce a frame shift in the subsequent transcript and protein, either leading to nonsensemediated decay or an entirely different structure downstream of the indel.

Single nucleotide variants (SNVs) are the smallest type of genetic variant (Fig. 1), and are by far the most thoroughly used in genetic association studies. In protein coding sequence, SNVs can change codons to alter the eventual sequence of amino acids in the protein (missense variant), introduce a premature STOP codon (nonsense variant), or alter splicing properties (splice variants). SNVs may also change the codon to another codon for the same amino acid (synonymous variants). SNVs in a noncoding sequence may exert an effect by altering binding affinities for DNA-binding proteins, such as transcription factors, or by affecting epigenetic properties of the chromatin, such as DNA methylation. These single-letter changes to the genetic code are, from a technical standpoint, the easiest class of genetic variation to identify in a massively parallel way, which led to them being the basis for the first generation of GWAS. SNVs that are common in the population are called single-nucleotide polymorphisms (SNPs), and these are the variants that are probed by the microarrays used in massive studies like those of the Psychiatric Genomics Consortium (PGC; http://pgc.unc.edu). Because SNPs are common in the population, they have generally withstood a reasonable amount of selective pressure, and, consequently, associations between a SNP and a deleterious condition such as a disease will generally have a small effect size. Such small effects require large studies to provide the power necessary to declare a statistically significant association. However, rare SNVs (or any kind of rare genetic variant) have generally not undergone the same level of purifying selection, and so disease associations can have larger effect sizes. However, owing to the rarity of these variants, they are often pooled within a gene or even a gene set or pathway to provide the necessary power to demonstrate a statistically significant association. A number of properties of SNPs plagued early GWAS [24], including confounding effects with population structure, as well as underpowered designs (as common SNP effects are small and require large samples to achieve significance). Furthermore common SNPs often merely tag causal variants by virtue of their "hitchhiking" together through recombination events (contributing to a phenomenon called linkage disequilibrium). This tagging effect can make locating and interpreting the causal variant a challenging exercise.

\section{Technologies}

Two basic technologies dominate current genetic studies of psychiatric conditions: DNA microarrays and high-throughput sequencing (Fig. 1). Microarrays use DNA oligonucleotide probes, which give a sparse picture of the genome, to genotype SNPs and CNVs. The low cost of these arrays (typically around \$100-200) enabled the massive GWAS projects of the past decade, to the point that "microarray" and "GWAS" have become nearly synonymous. While the future is clearly in sequencing technologies (see below), microarray platforms, particularly those with custom probe content (such as the Illumina PsychArray, which probes an assortment of variants nominated by researchers in psychiatric genetics) still have their place in certain study designs. Specifically, in studies where assessment of common genetic risk is prioritized over gene discovery, microarrays can be a cost-effective tool.

As DNA sequencing prices have fallen dramatically over the past decade, investigators have more options to consider 
when designing genetic studies [25]. Whole-exome sequencing (WES) was the first form of high-throughput sequencing to be widely adopted in psychiatric genetics studies, with early studies in autism demonstrating enrichment of deleterious protein-coding mutations [26-29]. In WES, a preliminary capture step is performed that limits input DNA to protein-coding exons, thus reducing the DNA to be sequenced by more than an order of magnitude. While cost was the major consideration that birthed WES as a stopgap technology, investigators found that in contrast to GWAS, where top hits were often in functionally ambiguous noncoding regions, data from WES were comparatively straightforward to interpret: changes to coding DNA sequence affect splicing and aminoacid sequence of the resulting protein in a relatively straightforward way.

As sequencing throughput continues to increase with new technology, the price differential between WES and wholegenome sequencing (WGS) is shrinking. A whole genome sequence currently costs around 2 to 3 times the cost of an exome, yet yields $\sim 30$ times more data. Furthermore, the protein-coding fraction of the genome is covered more uniformly in WGS [30], and SVs can be called far more reliably and comprehensively in WGS. However, compared with WES, all these additional data require a substantial investment in storage and computational infrastructure, as well as the expertise to interpret noncoding variation. By far the most widely used technology for WGS is Illumina's sequencing by synthesis, which sequences about 150 base pairs (75-300 base pairs, depending on the instrument and chemistry) of the ends of DNA fragments. While Illumina's technology has proven popular and cost-effective, short-read (SR) approaches to sequencing have limitations. SR cannot read through long STRs, and consequently cannot always genotype them. SR can only be used for short-range phasing of variants; it struggles to resolve complex structural variation and lowcomplexity sequences. Competitors have focused on developing long-read technologies in the hope of luring customers who have run into Illumina's limitations. PacBio uses a single-molecule real-time approach to achieve reads averaging $>10 \mathrm{~kb}$ [31]. This technology was demonstrated to great effect in the sequencing of a hydatidiform mole genome, resulting in a far more comprehensive view into SVs than can be provided by Illumina's technology [32]. This work also enabled the closure of many interstitial assembly gaps in the human reference genome. While PacBio's technology delivers impressive results and throughput is improving, its high cost pushes it out of the reach of most laboratories and makes it a poor solution for sequencing large cohorts. A somewhat more cost-effective approach to long-read sequencing has been developed by 10X Genomics [33], called linked read sequencing. This approach uses microfluidics to partition high-molecular-weight DNA molecules into droplets where barcodes are added to amplified fragments, thus introducing the means to "link" the resulting sequencing reads back to a single DNA molecule. The library is sequenced on standard Illumina instrumentation, and a custom alignment and variantcalling pipeline is used to identify and phase SNVs, indels, and SVs. On average, $97 \%$ of SNVs were phased into phase blocks ranging from 0.9 to $2.8 \mathrm{Mb}$ in length [33].

While WGS is a powerful technology for comprehensive discovery of genetic variations, targeted sequencing offers a more economical approach for replication studies or other hypothesis-driven designs that target a smaller number of genes and loci. Technologies such as Agilent's SureSelect use RNA probes to capture targeted genomic regions prior to sequencing library preparation. Another cost-effective approach to targeted sequencing is molecular inversion probes [34]. These are linear DNA oligos whose ends target sequences that flank regions of interest of about 200 base pairs. A gap filling and ligation reaction fills in the targeted sequence and the probe is circularized, the residual linear DNA digested, and the circular capture products amplified through PCR. The pool of PCR products is then sequenced with standard Illumina chemistry. Although the up-front investment in the synthesis of the oligo probes can be substantial, the number of individuals that can be sequenced with the resulting probe pools is, for all practical purposes, limitless. Cost analyses suggest that a panel of 1000 targeted regions can be sequenced for $<\$ 10 /$ per individual [35].

\section{Concepts}

Here I introduce some concepts that come up routinely in psychiatric genetics. While some of these concepts are illustrated with examples from the field, the major findings are presented in more detail in the "Current Trajectories" section.

GWAS data have seen a renaissance in recent years with an increasing appreciation of the role of common polygenic risk [36-39]. Focus has shifted from array-based GWAS data as the primary means of disease gene discovery to microarrays as a tool to calculate the aggregate genetic risk of individuals for various diseases. Predictive models are trained using large discovery cohorts, such as from the PGC, and then a linear combination of risk alleles is computed in the cohort of interest for each individual, essentially producing a single numerical value for each individual that represents their polygenic risk for the disease in question. These polygenic risk scores are then correlated with other variables of interest to draw inferences about the role of common polygenic risk in the phenotypes of interest. Such analyses, using either a polygenic risk score or an alternative approach called LD score regression [40], are often referred to as studies of genetic correlations [41, 42]. Notable examples of the application of polygenic risk scores in the general population include the finding that polygenic risk for autism is positively correlated with 
cognitive ability [37] and that polygenic risk for SZ is predictive of creativity [38]. Such examples may serve to explain, at least in part, the evolutionary double-edged sword of polygenic psychiatric risk. Furthermore, it has been shown through genetic correlations that major depressive disorder, bipolar disorder, and SZ share genetic risk factors; and that anorexia and SZ share genetic risk factors [41]. A further permutation of the concept of polygenic risk is the use of predictive models to infer gene expression (rather than disease risk) based on large-scale genotyping data [43, 44]. In this way, the collection of imputed gene expression values may be used as an intermediate phenotype to link trait or disease state to genotype.

As parallel efforts to discover the genetic basis for different common psychiatric conditions have progressed, it has become clear that a substantial number of risk genes confer risk for multiple conditions [42], a phenomenon called pleiotropy [45]. Consequently, the notion that there are "schizophrenia genes" and "autism genes", and so on, has evolved into the idea that there are simply "brain genes" that can be perturbed in ways and combinations so as to predispose individuals to either SZ or autism or any other neuropsychiatric condition [46]. Certain classes of genes may be more likely to be involved in one condition than another [e.g., chromatin and transcriptional regulators in autism spectrum disorder (ASD)], but the field is young enough that it is difficult to determine whether or not these perceptions of thematic segregation by condition are merely a product of ascertainment bias.

A very specific kind of pleiotropy has been observed in connection with some well-studied CNVs: reciprocal (or mirror) phenotypes. When a deletion and its reciprocal duplication (i.e., of the same genetic material) results in phenotypes that are correspondingly mirrored at opposite ends of a spectrum, that locus is said to be involved in a reciprocal phenotype. The implication is that phenotypes associated with these loci vary in a semi-quantitative way with gene dosage. Notable examples include variation of head circumference (i.e., trends toward microcephaly or macrocephaly) and body mass index with comorbid neuropsychiatric features observed in $16 \mathrm{p} 11.2$ [47, 48], head circumference in 1q21.1 [49], and head circumference, stature, and bone maturation rates at $5 \mathrm{q} 35$ [50]. Reciprocal CNVs at a number of genomic loci that confer reciprocal risk for autism or SZ (1q21.1, 16p11.2, $22 q 11.21$, and $22 q 13.3$ ) have led to a hypothesis that, in some respects, these 2 conditions might be considered reciprocal phenotypes [51].

As sequencing prices have continued to fall, it has become practical to sequence large numbers of trios with the aim of identifying putatively causal de novo mutations (DNMs). These are new mutations that do not affect the parents but that occur sporadically in either the sperm or egg haploid genomes, thus propagating to all cells in the offspring. This approach to gene discovery is particularly fruitful when family history is strongly suggestive of the condition being sporadic: the proband's genome is compared with the parents' genomes, and genetic variants that are absent in both parents are candidate DNMs (sequencing errors lead to many false-positives and best practices require confirmation of putative DNMs with an additional genotyping technology). Early exome studies of autism rapidly expanded the list of autism risk genes by identifying genes that were hit by de novo and presumed damaging mutations in multiple individuals [26-29]. Further, these studies showed that individuals with autism do not have a greater burden of exonic DNMs, although their DNMs are more likely to be damaging. WGS studies of autism and other samples showed that a disproportionate number of DNMs $(\sim 75 \%)$ are transmitted from the father, that DNM burden is positively correlated with paternal age (about 1 DNM per year of paternal age), that DNMs cluster together in a nonrandom fashion, that humans harbor about 50 to 100 single-nucleotide DNMs each, and that single-nucleotide mutation rate varies substantially across the genome [52, 53]. As DNMs have undergone only a single round of selective pressure, they are attractive candidates for potentially causal variants of large effect.

Depending on the comprehensiveness of the genetic study, there may be many thousands of variants of interest, and a variant annotation scheme must be used to prioritize candidates for further investigation. For protein-coding variants, indicators of the functional consequence (amino-acid change, premature STOP codon, splice-site disrupting, etc.) can be assigned in a straightforward manner. Variants are also annotated according to the frequency of the minor allele in a population sample, and this is used to classify the variant as common or rare (with thresholds varying, but usually either $<0.05$ or $<0.01$ qualifies as rare). Measures of selective constraint, such as PolyPhen [54], Genomic Evolutionary Rate Profiling (GERP) [55], or Combined Annotation Dependent Depletion (CADD) [56] are often used as an indicator of how deleterious the variant is. In addition, noncoding variants are sometimes annotated according to whether they intersect known regulatory elements or epigenetic marks, which may give further clues as to their regulatory consequences.

The impact of a genetic variant does not occur in a vacuum; it is often modulated by other genetic factors or the environment. This modulatory effect can result in incomplete penetrance (when some carriers of a damaging variant do not show the corresponding phenotype) or variable expressivity (when the associated phenotype manifests itself differently in individuals). When the effect of a variant depends upon the genetic background of an individual or the genotype at another locus, the effect is said to be epistatic. Epistatic effects are often called gene-gene interactions, and 
epistasis has been used in model organisms as a means to flesh out functional gene networks [57], though in humans the phenomenon has not been observed as extensively. Nevertheless, clear examples of epistasis have been observed in human neuropsychiatric and developmental conditions [58-64].

In a way that is comparable to epistasis, the sex of the variant carrier can have a decisive effect on the phenotypic expression of the variant. Perhaps the most striking example of this is the well-known male bias in ASD [65]. This work has led to a broader idea of the "female protective effect" in neurodevelopment in general [66-68], where females can carry higher levels of genetic risk than males, while remaining largely asymptomatic. The idea of a female protective effect is attractive, in part, because of its therapeutic implications: if the biological pathways that make females more resilient in the face of genetic insult can be better understood, then perhaps they can be exploited to therapeutic effect $[66,68,69]$. The level of sexual dimorphism in neuropsychiatric conditions varies along a spectrum ranging from extreme male bias in autism and other neurodevelopmental conditions to extreme female bias in eating disorders and anxiety [70]. Because of the crucial role that sex plays in the phenotypic expression of genetic conditions, it should be a core factor in experimental designs, and not ignored for convenience sake.

As with sex, the environment can play a crucial modulatory role in the expression of genetic disease, including autism [71, 72], major depression [73], SZ [74, 75], and others. The prototypical example of the gene-environment interaction in neuropsychiatry is post-traumatic stress disorder (PTSD) [76, 77], where not all individuals who suffer a traumatic event develop PTSD. It is thought that there is a latent genetic risk that, when combined with a traumatic event, manifests as PTSD.

\section{Current Trajectories of Genetic Discovery}

In the wake of the completion of the Human Genome Project, psychiatric geneticists have exploited the above technologies and concepts to learn more about the biological nature of neuropsychiatric conditions. Below I provide a brief synopsis of the recent trajectory of genetic discovery for some of the major neurodevelopmental and neuropsychiatric conditions. Emphasis is given to neurodevelopmental conditions, and these are not intended to be comprehensive; indeed, the breadth of the field makes a comprehensive review impossible. Rather, the goal is to illustrate patterns of inquiry currently in use across conditions. Table 1 summarizes the various consortia and working groups (with websites, where available) undertaking research in each condition. While not exhaustive, Table 1 focuses mostly on consortia that have demonstrated their productivity through multiple peer-reviewed publications over the last 5 years.

\section{Intellectual Disability}

Intellectual disability (ID) is a genetically heterogeneous neurodevelopmental disorder characterized by impaired adaptive functioning and low IQ. Prevalence of ID is estimated to be between $0.05 \%$ and $1.55 \%$ [78]. ID is often a comorbidity in other neuropsychiatric conditions $[79,80]$ and is especially prevalent in SZ and ASD, as well as attention deficit/ hyperactivity disorder (ADHD) [81]. Because of its profound effect on fecundity, severe ID is presumed to be largely monogenic and not familial [82], though the total number of risk genes has yet to be enumerated. At the same time, ID has varying levels of severity and it has been shown that some less severe forms of ID are the result of complex polygenic inheritance [82], essentially representing the lower range of intelligence, which itself has been shown to have a heritability of 0.4 to 0.8 [83].

ID has classically been linked to large-scale structural variations in the genome, and these have been extensively reviewed [84]. Recent WGS and WES studies, which can resolve deleterious genetic variants at a much finer resolution, have shored up known ID genes, discovered new ones, and demonstrated emergent patterns. One recent study [85] performed WGS on 50 individuals diagnosed with severe ID and their unaffected parents and found a clear genetic cause in $42 \%$ of the subjects (this was estimated to generalize to a rate of $62 \%$ in a new sample where microarray and WES analyses had not already been performed). This study, like others, found an excess of protein-coding de novo mutations, as well as enrichment of de novo hits among a list of 528 known ID genes. The use of WGS was vindicated by the discovery of several de novo SVs that escaped detection by microarray technology. As expected, slightly lower diagnostic yields are obtained with WES [86]. More recently, a meta-analysis of $>$ 2000 trios with ID found statistical associations of rare and de novo variants in 10 newly identified candidates: $D L G 4$, PPM1D, RAC1, SMAD6, SON, SOX5, SYNCRIP, TCF20, TLK2, and TRIP12 [87]. These genes were shown to be intolerant to functional nonsynonymous variants.

As a complement to the unbiased, genome-wide studies, many recent studies have followed the "genotype-first" approach [88], where a sample of individuals carrying damaging mutations in the same gene is assembled, and then characterized extensively from a phenotypic standpoint. Examples include POGZ [89], DYRK1A [90], TBCK [91], EBF3 [92], CHAMP1 [93], and IARS [94].

Inborn errors of metabolism represent a well-known cause of ID [95], and are attractive from a research perspective because of the potential for addressing or even preventing negative outcomes through dietary supplementation or restriction $[95,96]$. Well-studied examples include phenylketonuria [97], defects in creatine transport [98], branched-chain amino-acid metabolism [99, 100], 


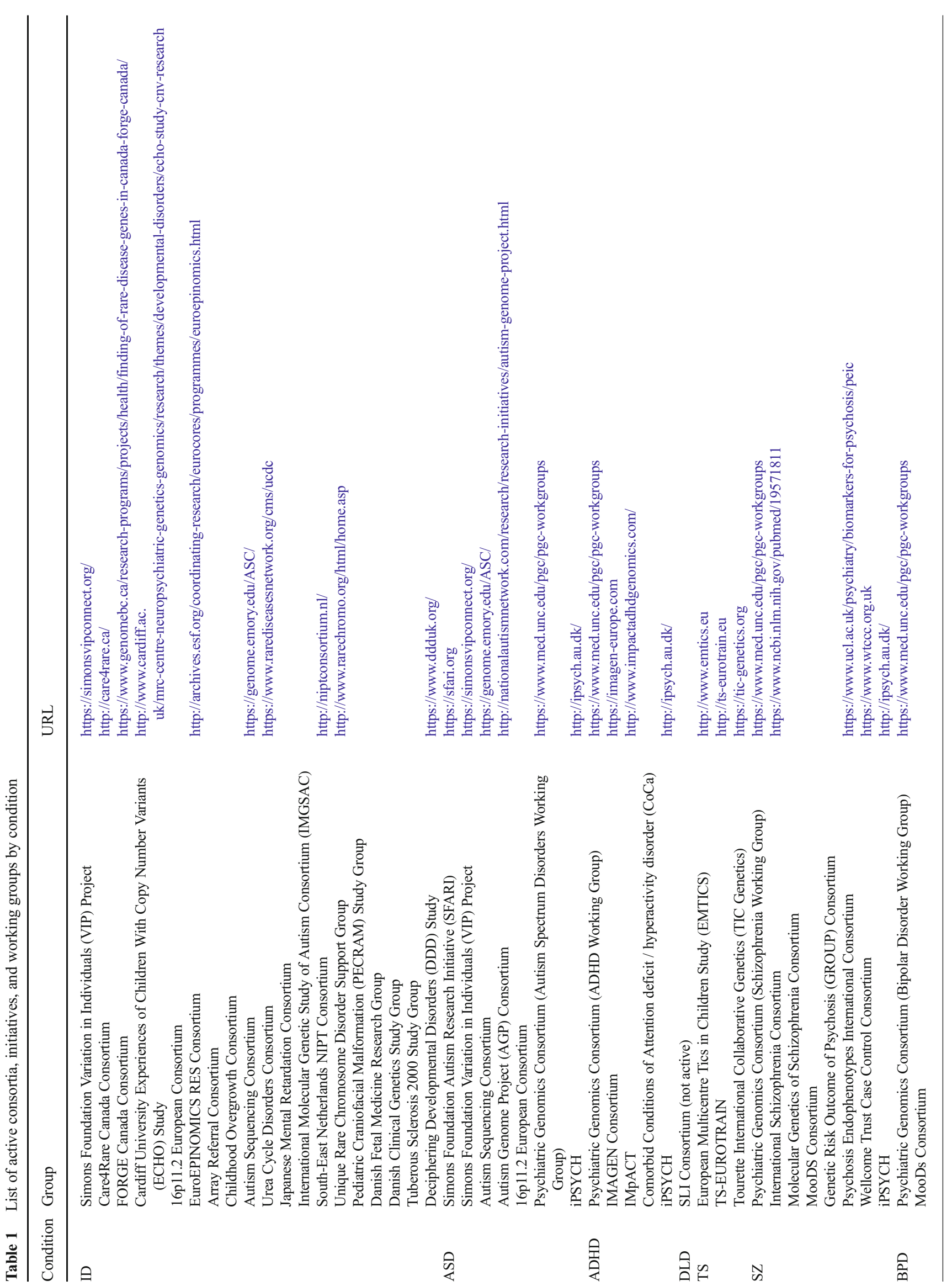


glycosylation [101], and lysosomal storage disorders [102]. A recent network analysis of ID risk genes underscored the central role of metabolic pathways, and highlighted other areas of convergence in ID, including genes involved in nervous system development, RNA metabolism, transcription, hedgehog signaling, glutamate signaling, peroxisomes, glycosylation, and cilia [103].

A number of pharmacological strategies targeting ID are under development [104]. Risperidone was shown in early studies to significantly ameliorate problematic behaviors $[105,106]$, though significant side effects temper enthusiasm about its use [107]. Furthermore, because it does not directly target pathways known to be dysregulated in ID, it cannot be considered a specific therapy for ID. Other approaches justified by the known molecular pathologies have been investigated including mGluR5 antagonists [108-111], ampakines [112-114], and $\gamma$-aminobutryic acid $\mathrm{B}$ agonists [115]. The mTOR pathway has also been a target of drug development in the context of ID [116], where rapamycin and other inhibitors of mTOR function show promise [117].

\section{ASD}

ASD is a phenotypically and genetically heterogeneous collection of neurodevelopmental conditions that entail impairments in social communication and restrictive and repetitive behaviors. Heritability of ASD ranges widely depending on study design and confounds, but recent estimates put it at 0.5 to $0.54[36,118]$. Current estimates of prevalence are at 1 in 68 [119], and ASD encompasses enormous phenotypic diversity, from profoundly affected nonverbal individuals with comorbid ID to highly intelligent but socially impaired individuals. Correspondingly, there is no single genetic architecture for ASD. Some well-known monogenic syndromes show ASD as a common feature, including Rett syndrome (MECP2), Fragile $\mathrm{X}$ syndrome (FMR1), and Angelman syndrome (UBE3A). However, recent work has shown that most risk for ASD lies in the cumulative effect of thousands of common risk variants [36]. It is estimated that there are likely hundreds of ASD risk genes [26], and recent coordinated and individual efforts have been aimed at enumerating them. No other neurodevelopmental condition has been investigated with sequencing technology as intensively as ASD, and many early analytical and methodological advances were made to enable the analysis of ASD sequencing data [120-122].

In contrast to sequencing studies, ASD GWAS projects have yet to suggest robustly associated loci, and data from these studies have shown more traction in developing polygenic risk scores for ASD [37, 123] than for gene discovery. Array-based CNV studies have been more productive from a locus discovery perspective, through their 
focus on detecting rare variation [14, 124]. In 2012, a series of coordinated WES studies of ASD were published that used de novo mutation as a means for gene discovery [26-29]. Shortly thereafter came the first WGS studies of autism $[52,125]$. These studies, especially the WES studies with their larger numbers, quickly expanded the list of candidate ASD genes, and multiple follow-up studies confirmed the association of some of these genes with ASD, notably CHD8, DYRK1A, GRIN2B, TBR1, PTEN, and TBL1XR1 [126], POGZ [89], and ADNP [127]. One emerging theme is that ASD risk genes are likely to be regulatory targets of fragile $\mathrm{X}$ mental retardation protein (FMRP), the protein encoded by the Fragile $\mathrm{X}$ gene, FMR1 [27]. Other risk genes are involved in synaptic structure and integrity, such as neuroligins/neurexins [128, 129], SHANK proteins [130], and contactin proteins [131]. Still other ASD risk genes are involved in broad regulation of chromatin structure and transcriptional regulation, such as CHD8 [28, 29, 126, 132, 133], TBRI $[126,134]$, and TCF4 [132, 135].

Effective treatment options for ASD are likely to be highly individualized, owing to the extensive heterogeneity of the condition. Indeed, much of the most promising treatment development work is done in genetically defined forms of ASD, such as Fragile X [136], Rett syndrome [137-139], and others $[100,140-143]$.

Several consortia and foundations have been and continue to be driving forces in ASD genetics. The Simons Foundation has built extensive infrastructure and data sets for ASD researchers to use, including SFARI gene, which offers a curated list of ASD candidate genes. In addition, sequencing data and biospecimens from the Simons Simplex Collection are available to qualified investigators. The Simons Foundation also sponsors the Variation in Individuals Project, which focuses on genetically defined forms of ASD such as 16p11.2 and 1q21.1. Other consortia and projects actively contributing to research in the genetics of ASD include the ARRA Autism Sequencing Collaboration, the Autism Genome Project Consortium, the 16p11.2 European Consortium, and the Psychiatric Genomics Consortium.

\section{ADHD}

ADHD is a highly heritable neurodevelopmental condition that presents with impairments in sustaining attention and an inability to control impulses and activity level. In addition to the previously mentioned comorbidity with ID, ADHD shows high comorbidity with ASD within individuals and family members [144]. Prevalence of ADHD is estimated at $5 \%$ to $7 \%$ in children $[145,146]$ and $3 \%$ to $5 \%$ in adults $[147,148]$. Twin studies estimate high heritability $(70-80 \%[149,150])$, and ADHD is genetically heterogeneous and a host of candidate genes have been suggested [151-153]. Candidate gene studies (i.e., where only one or a handful of polymorphisms are studied) suffer from ascertainment bias, and many of the positive associations in candidate gene studies of neurotransmitter pathway genes are not represented in genomewide studies, where a higher burden of proof exists owing to multiple hypothesis testing. However, some integrative analyses have indicated that pooling of common variants within these neurotransmission pathways may lead to statistical significance $[154,155]$.

Perhaps the most compelling theme to emerge from the genome-scale studies of ADHD is glutamatergic neurotransmission. A large study of CNVs implicated metabotropic glutamate receptors, as well as functionally related genes, in the etiology of ADHD [156]. This work led to the repositioning of the drug NFC-1 (fasoracetam monohydrate), which stimulates metabotropic glutamate receptors, for treatment of ADHD in individuals with confirmed mutations in mGluR genes (clinical trial ID NCT02777931). A subsequent study of CNVs in ADHD also found a link to metabotropic glutamate receptors [157]. Imaging studies have suggested abnormal glutamate levels in cortical and subcortical brain regions [158]. Glutamatergic signaling has gradually emerged as a point of overlap between ADHD and ASD [159, 160]. Methylphenidate, a common medication for ADHD that acts as a dopamine-norepinephrine reuptake inhibitor, was found to modulate the number of surface glutamate receptor subunits in a dose-dependent, bidirectional fashion [161]. Furthermore, genetic variation in GRM7 was associated with response to methylphenidate [162].

Synaptic adhesion molecule LPHN3, which regulates synaptic density and development [163], was found to be associated with ADHD by a linkage study [164] and has been robustly replicated since then [165-175]. LPHN3 variants have been shown to be predictive of methylphenidate response in ADHD [173]. FLRT3 encodes a ligand for LPHN3 [176-178], and has itself shown suggestive genetic associations to ADHD [179-182].

Other studies of rare variation in ADHD have implicated signal transduction genes NT5DC1, PSD, SEC23IP, and ZCCHC4 [183], and a small-scale exome sequencing study found a significant excess of rare variation in 51 preselected ADHD candidate genes [184].

\section{Developmental Language Disorder}

Developmental Language Disorder (DLD), also known as specific language impairment, language impairment, or language disorder, is a neurodevelopmental condition that impairs expressive and receptive language ability that is not attributable to hearing loss or severe ID. Prevalence is estimated at 7\% [185] and heritability is moderate to high [186-189]. It 
is highly comorbid with ADHD, with $\sim 40 \%$ of individuals with DLD also having an ADHD diagnosis [190].

Early genetic studies of language ability were driven by pedigrees with very pronounced phenotypes, and these led to seminal discoveries such as disruptive variation in FOXP2 being associated with impaired language abilities [191-194]. However, subsequent studies of common variation have not been able to provide strong support for these genes playing a major role in DLD $[195,196]$. Genome-wide studies of common variation are generally woefully underpowered and have not produced findings that withstand multiple testing correction [197, 198].

A recent study that combined GWAS and exome sequencing in an isolated population implicated SETBP1 as a language-associated gene, and this association was replicated in an admixed sample [199]. Furthermore, through exome sequencing of the most severely affected individuals in the sample, a number of putatively disrupting variants were found and, together with GWAS candidates, these genes were enriched as transcriptional targets of MEF2A. WES was used in another study that implicated NFXL1, and then confirmed the association with language ability in 2 other samples [200]. These studies illustrate that movement toward sequencing technologies will bear fruit because of its ability to combine analysis of common and rare variation together.

\section{Tourette Syndrome}

Tourette syndrome (TS) is a neurodevelopmental condition that presents with disruptive motor and vocal tics [201]. Although early work suggested a monogenic, autosomal dominant mode of inheritance [202], subsequent findings demonstrated substantial genetic and phenotypic heterogeneity [203-205]. TS shows strong comorbidities with obsessivecompulsive disorder and ADHD [206], with other mood, anxiety, and disruptive behavior disorders occurring in about $30 \%$ of probands. While many of the specific genes underlying TS remain elusive, over the last decade, histidine decarboxylase, a key enzyme in the biosynthesis of histamine, has emerged from human genetic studies as an important player in the etiology of the disease [207-209], with animal models displaying TS-like phenomenology [210] and implicating an interaction between dopaminergic and histaminergic systems in the basal ganglia. Administration of haloperidol and histamine were shown to rescue TS-like behavioral and molecular characteristics in this model.

A number of common variant studies of TS have been carried out, some at the genome-wide scale, with less conclusive results. The first GWAS of TS failed to reach significance for any SNP [211]. A follow-up study [212] that included 42 of the top candidates from the initial GWAS found a significant association at rs2060546, near the gene that encodes the axon guidance protein netrin 4 (NTN4), which shows strong expression in the striatum. A recent attempt at replicating this association failed [213]; however, a meta-analysis of 3 cohorts showed significance and consistent direction of effect.

Several consortia are currently undertaking large-scale genetic studies of TS. The European Multicentre Tics in Children Study (EMTICS) seeks to elucidate gene-environment interactions, including the involvement of infection and immune mechanisms in TS etiology. Two patient cohorts form the basis of EMTICS: the ONSET study involves follow-up of 375 high-risk children aged 3 to 10 years who have an immediate family member with a diagnosis of TS and at study entry have no tics. COURSE is a longitudinal study that is following 700 children and adolescents (aged 3-16 years) with a known chronic tic disorder or TS. The study began in March 2013 and the study will conclude in 2017.

TS-EUROTRAIN is a training network that acts as a platform to unify large-scale TS studies and educate the next generation of experts. TS-EUROTRAIN is notable for completing the first epigenome-wide association study for tics, analyzing data from the Netherlands Twin Register [214]. This study interrogated 411,469 autosomal methylation sites in 1678 individuals. Although no site reached genome-wide significance, the top hits include several genes and regions previously associated with neurological disorders and warrant further investigation.

The Tourette International Collaborative Genetics (TIC Genetics) study $[215,216]$ is currently finishing analysis of WES data from 325 simplex TS trios, with the main focus being the detection of de novo SNVs and indels.

\section{Adult-Onset Disorders}

\section{Schizophrenia}

Schizophrenia (SZ) is a complex, highly heritable, and heterogeneous psychiatric disorder that presents with positive (psychosis, hallucinations) and negative (apathy, blunted affect, social withdrawal, poverty of speech, anhedonia) symptoms, with associated cognitive deficits. Its prevalence is estimated at $1 \%$ [217] and it is highly heritable $(65-81 \%$ [218, 219]). Significant comorbidities include substance abuse (47\%) and depression (50\%), as well as anxiety disorders (29\% PTSD, $15 \%$ panic disorder, and $23 \%$ obsessive-compulsive disorder) [220]. Despite the wide appreciation of the genetic roots of SZ, its etiology and origins are still not fully understood [221], though some recent exciting progress has been made that is beginning to chip away at the complex physiology that underlies SZ.

It is clear that SZ is polygenic [222, 223], and, indeed, the most compelling study of the last several years identified 108 loci as SZ-risk loci [224]. One of these hits resides in the major histocompatibility complex, a notoriously difficult region to resolve from a genotype standpoint. Despite this challenge, 
recent work that focused on elucidating the underlying source of the association signal in this region found that the complement component gene $\mathrm{C} 4$ drives the underlying association, and that risk alleles result in higher expression of $\mathrm{C} 4 \mathrm{~A}[225$, 226]. C4 protein is expressed at the synapse and plays a role in synaptic pruning, thus implicating overactive synaptic pruning as a mechanism underlying schizophrenia risk.

A recent large-scale WES study of SZ [222] implicated voltage-gated calcium ion channels and proteins comprising the ARC postsynaptic protein complex as harboring an overabundance of putatively functional rare variation. As has been noted for genes affected by damaging variation in ASD [27], this study showed an enrichment of FMRP targets affected by damaging variation in SZ probands. These and other genetic findings implicate synaptic genes as a major theme in the genetic etiology of SZ [227], suggesting that development of therapeutics should involve the targeting of synaptic proteins and processes.

\section{Bipolar Disorder}

Bipolar disorder (BPD) is a heritable psychiatric condition marked by alternating episodes of mania and depression. Prevalence is $2 \%$ to $3 \%$ [228], and heritability may be as high as $80 \%$ [229]. Individuals with BPD are at an 8- to 10 -fold increased risk for suicide [230]. BPD is a complex and genetically heterogeneous condition; however, compared with other conditions such as SZ, discovery of genetic risk factors robustly and specifically connected to the condition has been slow. The largest GWAS in BPD to date [231] showed associations in 4 known (MAD1L1, $6 \mathrm{q} 16.1, D D N$, and TRANK1) and 2 novel loci (intergenic 9p21.3 and intronic variants in ERBB2). Exome sequencing in a large cohort of familial BPD showed an enrichment of predicted damaging variation in genes previously associated with ASD and SZ, as well as targets of the fragile X protein, FMRP [232], suggesting overlapping genetic risk with these disorders. The trickle of genetic findings in BPD, in contrast to its high heritability, speak to the extensive complexity and heterogeneity of the disorder, and support the need for larger studies of this condition. In the near term, perhaps one of the most promising approaches is in the genetics of lithium response, reviewed in detail in this issue.

\section{Major Depressive Disorder}

Major depressive disorder (MDD) is characterized by prolonged depressed mood or loss of interest or pleasure in nearly all activities, together with other disturbances in areas such as sleep, appetite, and psychomotor activity. Its prevalence varies by geographic location but is mostly $8 \%$ to $12 \%$ $[233,234]$, and women show more susceptibility than men.
Significant comorbidities include dysthymia (20\%) and anxiety disorders $(21 \%)$ [235] . Heritability is estimated at about $37 \%$ [236, 237]; however, like BPD, genetic findings that provide compelling biological insights into the disorder have been elusive [238]. Nevertheless, recent studies show promise. The largest MDD GWAS to date, which used data from direct-to-consumer genetics company 23 andMe, uncovered 15 loci associated with MDD [239]. Another study used low-coverage WGS and identified SIRT1 and LHPP as potential MDD risk genes [240].

While genetic studies of MDD have not yet yielded enough robust results for pathway analyses to gain traction, a recent gene expression study of individuals with MDD implicated inflammation/immune pathways (specifically interleukin-6 and natural killer signaling pathways) as a marker of MDD [241]. DVL3, a gene that regulates cell proliferation and previously implicated by PGC results [242], was also found to be differentially expressed in this analysis. These findings raise the possibility of targeting inflammation pathways as a means to treat depression [243].

\section{Conclusion}

Human genetic studies have been the driving force in bringing to light the underlying biology of psychiatric conditions. The complex nature and genetic heterogeneity of these conditions requires vast sample sizes to power statistically robust associations, and such studies can only be accomplished through continued intra- and international collaboration and an increase in data sharing. While these massive collaborative efforts are necessary for gene discovery, individual laboratories and investigators still play a vital role in contextualizing and deepening our understanding of these genetic associations through focused and hypothesis-driven investigation.

As a complement to these gene-discovery efforts, it is clear that much of the future of psychiatric genetics lies in the "genotype-first" approach to studying genetically defined neuropsychiatric conditions. These studies, which are perhaps the greatest near-term boon that genetics can bestow on therapeutic research, can inform the design of clinical trials and improve the odds of their success while providing crucial insight into the penetrance and variable expressivity displayed among carriers of functionally comparable genetic variations. The Simons Variation in Individuals Project project provides a useful model for considering the promise and the challenges of clustering patients by genetic etiology. Furthermore, emerging online patient networks such as patientslikeme.com and the Interactive Autism Network, though not explicitly genetically defined, also show potential in the way they remove geographic boundaries and allow self-clustering of patients.

From a technological standpoint, microarray technology is waning, though for certain applications it remains an 
economical option. Sequencing approaches, and, in particular, WGS, allow for comprehensive discovery of all modes and frequencies of genetic variation, not just those designed into an array. Cost and analytical expertise are the prevailing barriers for wider adoption, but these are rapidly diminishing.

Common polygenic risk is becoming a useful tool for comparing the shared genetic basis of disparate psychiatric conditions, for stratifying population samples according to their polygenic risk as part of the study design, as well as for studying genetic correlates in the general population while drawing conclusions about the link between psychiatric risk and traits that may be under positive selection (such as creativity or cognitive ability).

Finally, as genetic and other molecular studies of psychiatric conditions increase our understanding of the basic biology of these disorders, we may find that drugs (or supplements) already on the market may be repurposed to treat underlying causes that manifest as mental illness [100, 243].

Acknowledgments I thank Brooke McKenna, Dabney Hofammann, Kevin Vervier, Iman Dehzangi, Ethan Bahl, and Tanner Koomar for assisting in the review of the literature, as well as the anonymous reviewers for their constructive feedback. JJM received support from National Institutes of Health grants MH105527 and DC014489, the Simons Foundation (SPARK Clinical Recruitment Site at the University of Iowa), and the Brain and Behavior Research Foundation (NARSAD Young Investigator Award \# 22967).

Required Author Forms Disclosure forms provided by the authors are available with the online version of this article.

\section{References}

1. Kurahashi H, Tsutsumi M, Nishiyama S, Kogo H, Inagaki H, Ohye T. Molecular basis of maternal age-related increase in oocyte aneuploidy. Congenit Anom (Kyoto) 2012;52(1):8-15.

2. Jiang J, Jing Y, Cost GJ, et al. Translating dosage compensation to trisomy 21. Nature 2013;500(7462):296-300.

3. Antonarakis SE. Down syndrome and the complexity of genome dosage imbalance. Nat Rev Genet 2017;18(3):147-163.

4. Blackwood DH, Fordyce A, Walker MT, St Clair DM, Porteous DJ, Muir WJ. Schizophrenia and affective disorderscosegregation with a translocation at chromosome $1 \mathrm{q} 42$ that directly disrupts brain-expressed genes: clinical and P300 findings in a family. Am J Hum Genet 2001;69(2):428-433.

5. Alkan C, Coe BP, Eichler EE. Genome structural variation discovery and genotyping. Nat Rev Genet 2011;12(5):363-376.

6. Zhang F, Gu W, Hurles ME, Lupski JR. Copy number variation in human health, disease, and evolution. Annu Rev Genom Hum Genet 2009; 10:451-481.

7. Malhotra D, Sebat J. CNVs: harbingers of a rare variant revolution in psychiatric genetics. Cell 2012;148(6):1223-1241.

8. Iafrate AJ, Feuk L, Rivera MN, et al. Detection of large-scale variation in the human genome. Nat Genet 2004;36(9):949-951.

9. Sebat J, Lakshmi B, Troge J, et al. Large-scale copy number polymorphism in the human genome. Science 2004;305(5683):525528.

10. Itsara $\mathrm{A}, \mathrm{Wu} \mathrm{H}, \mathrm{Smith} \mathrm{JD}$, et al. De novo rates and selection of large copy number variation. Genome Res 2010;20(11):1469-1481.
11. Marshall CR, Noor A, Vincent JB, et al. Structural variation of chromosomes in autism spectrum disorder. Am J Hum Genet 2008;82(2):477-488.

12. Sebat J, Lakshmi B, Malhotra D, et al. Strong association of de novo copy number mutations with autism. Science 2007;316(5823):445-449.

13. Levy D, Ronemus M, Yamrom B, et al. Rare de novo and transmitted copy-number variation in autistic spectrum disorders. Neuron 2011;70(5):886-897.

14. Sanders SJ, Ercan-Sencicek AG, Hus V, et al. Multiple recurrent de novo CNVs, including duplications of the 7q11.23 Williams syndrome region, are strongly associated with autism. Neuron 2011;70(5):863-885.

15. Sebat J, Levy DL, McCarthy SE. Rare structural variants in schizophrenia: one disorder, multiple mutations; one mutation, multiple disorders. Trends Genet 2009;25(12):528-535.

16. Walsh T, McClellan JM, McCarthy SE, et al. Rare structural variants disrupt multiple genes in neurodevelopmental pathways in schizophrenia. Science 2008;320(5875):539-543.

17. Raychaudhuri S, Korn JM, McCarroll SA, et al. Accurately assessing the risk of schizophrenia conferred by rare copynumber variation affecting genes with brain function. PLOS Genet 2010;6(9):e1001097.

18. Bailey JA, Eichler EE. Primate segmental duplications: crucibles of evolution, diversity and disease. Nat Rev Genet 2006;7(7):552-564.

19. Stankiewicz P, Shaw CJ, Withers M, Inoue K, Lupski JR. Serial segmental duplications during primate evolution result in complex human genome architecture. Genome Res 2004;14(11):2209-2220.

20. Fan H, Chu JY. A brief review of short tandem repeat mutation. Genomics Proteomics Bioinforma 2007;5(1):7-14.

21. Labbadia J, Morimoto RI. Huntington's disease: underlying molecular mechanisms and emerging concepts. Trends Biochem Sci 2013;38(8):378-385.

22. Jin P, Warren ST. Understanding the molecular basis of fragile $X$ syndrome. Hum Mol Genet 2000;9(6):901-908.

23. 1000 Genomes Project Consortium, Abecasis GR, Altshuler D, et al. A map of human genome variation from population-scale sequencing. Nature 2010;467(7319):1061-1073.

24. Teo YY. Common statistical issues in genome-wide association studies: a review on power, data quality control, genotype calling and population structure. Curr Opin Lipidol 2008;19(2):133-143.

25. Goodwin S, McPherson JD, McCombie WR. Coming of age: ten years of next-generation sequencing technologies. Nat Rev Genet 2016;17(6):333-351.

26. Sanders SJ, Murtha MT, Gupta AR, et al. De novo mutations revealed by whole-exome sequencing are strongly associated with autism. Nature 2012;485(7397):237-241.

27. Iossifov I, Ronemus M, Levy D, et al. De novo gene disruptions in children on the autistic spectrum. Neuron 2012;74(2):285-299.

28. Neale BM, Kou Y, Liu L, et al. Patterns and rates of exonic de novo mutations in autism spectrum disorders. Nature 2012;485(7397):242-245.

29. O'Roak BJ, Vives L, Girirajan S, et al. Sporadic autism exomes reveal a highly interconnected protein network of de novo mutations. Nature 2012;485(7397):246-250.

30. Turner TN, Hormozdiari F, Duyzend MH, et al. Genome sequencing of autism-affected families reveals disruption of putative noncoding regulatory DNA. Am J Hum Genet 2016;98(1):58-74.

31. Rhoads A, Au KF. PacBio sequencing and its applications. Genomics Proteomics Bioinforma 2015;13(5):278-289.

32. Chaisson MJ, Huddleston J, Dennis MY, et al. Resolving the complexity of the human genome using single-molecule sequencing. Nature 2015;517(7536):608-611.

33. Zheng GX, Lau BT, Schnall-Levin M, et al. Haplotyping germline and cancer genomes with high-throughput linked-read sequencing. Nat Biotechnol 2016;34(3):303-311. 
34. Cantsilieris S, Stessman HA, Shendure J, Eichler EE. Targeted capture and high-throughput sequencing using molecular inversion probes (MIPs). Meth Mol Biol 2017;1492:95-106.

35. Niedzicka M, Fijarczyk A, Dudek K, Stuglik M, Babik W. Molecular Inversion Probes for targeted resequencing in nonmodel organisms. Sci Rep 2016;6:24051.

36. Gaugler T, Klei L, Sanders SJ, et al. Most genetic risk for autism resides with common variation. Nat Genet 2014;46(8):881-885.

37. Clarke TK, Lupton MK, Fernandez-Pujals AM, et al. Common polygenic risk for autism spectrum disorder (ASD) is associated with cognitive ability in the general population. Mol Psychiatry 2016;21(3):419-425

38. Power RA, Steinberg S, Bjornsdottir G, et al. Polygenic risk scores for schizophrenia and bipolar disorder predict creativity. Nat Neurosci 2015;18(7):953-955.

39. Kong SW, Lee IH, Leshchiner I, et al. Summarizing polygenic risks for complex diseases in a clinical whole-genome report. Genet Med 2015;17:536-544.

40. Bulik-Sullivan BK, Loh PR, Finucane HK, et al. LD Score regression distinguishes confounding from polygenicity in genomewide association studies. Nat Genet 2015;47(3):291-295.

41. Bulik-Sullivan B, Finucane HK, Anttila V, et al. An atlas of genetic correlations across human diseases and traits. Nat Genet 2015;47(11):1236-1241.

42. Cross-Disorder Group of the Psychiatric Genomics C, Lee SH, Ripke S, et al. Genetic relationship between five psychiatric disorders estimated from genome-wide SNPs. Nat Genet 2013;45(9): 984-994.

43. Gamazon ER, Wheeler HE, Shah KP, et al. A gene-based association method for mapping traits using reference transcriptome data. Nat Genet 2015;47(9):1091-1098.

44. Vervier K, Michaelson JJ. SLINGER: large-scale learning for predicting gene expression. Sci Rep. 2016;6:39360.

45. Solovieff N, Cotsapas C, Lee PH, Purcell SM, Smoller JW. Pleiotropy in complex traits: challenges and strategies. Nat Rev Genet 2013;14(7):483-495.

46. Zhu X, Need AC, Petrovski S, Goldstein DB. One gene, many neuropsychiatric disorders: lessons from Mendelian diseases. Nat Neurosci 2014;17(6):773-781.

47. Golzio C, Willer J, Talkowski ME, et al. KCTD13 is a major driver of mirrored neuroanatomical phenotypes of the $16 \mathrm{p} 11.2$ copy number variant. Nature 2012;485(7398):363-367.

48. Jacquemont S, Reymond A, Zufferey F, et al. Mirror extreme BMI phenotypes associated with gene dosage at the chromosome 16p11.2 locus. Nature 2011;478(7367):97-102.

49. Brunetti-Pierri N, Berg JS, Scaglia F, et al. Recurrent reciprocal 1q21.1 deletions and duplications associated with microcephaly or macrocephaly and developmental and behavioral abnormalities. Nat Genet 2008;40(12):1466-1471.

50. Franco LM, de Ravel T, Graham BH, et al. A syndrome of short stature, microcephaly and speech delay is associated with duplications reciprocal to the common Sotos syndrome deletion. Eur J Hum Genet 2010;18(2):258-261.

51. Crespi B, Stead P, Elliot M. Evolution in health and medicine Sackler colloquium: comparative genomics of autism and schizophrenia. Proc Natl Acad Sci U S A 2010;107(Suppl; 1):1736-1741.

52. Michaelson JJ, Shi Y, Gujral M, et al. Whole-genome sequencing in autism identifies hot spots for de novo germline mutation. Cell 2012;151(7):1431-1442.

53. Kong A, Frigge ML, Masson G, et al. Rate of de novo mutations and the importance of father's age to disease risk. Nature 2012;488(7412):471-475.

54. Adzhubei I, Jordan DM, Sunyaev SR. Predicting functional effect of human missense mutations using PolyPhen-2. Curr Protoc Hum Genet 2013;Chapter 7:Unit7.20.
55. Cooper GM, Stone EA, Asimenos G, et al. Distribution and intensity of constraint in mammalian genomic sequence. Genome Res 2005;15(7):901-913.

56. Kircher M, Witten DM, Jain P, O'Roak BJ, Cooper GM, Shendure J. A general framework for estimating the relative pathogenicity of human genetic variants. Nat Genet 2014;46(3):310-315.

57. Costanzo M, VanderSluis B, Koch EN, et al. A global genetic interaction network maps a wiring diagram of cellular function. Science 2016;353:aaf1420.

58. Mitra I, Lavillaureix A, Yeh E, et al. Reverse pathway genetic approach identifies epistasis in autism spectrum disorders. PLOS Genet 2017;13(1):e1006516.

59. Fatjo-Vilas M, Prats C, Pomarol-Clotet E, et al. Involvement of NRN1 gene in schizophrenia-spectrum and bipolar disorders and its impact on age at onset and cognitive functioning. World J Biol Psychiatry 2016;17(2):129-139.

60. Schott BH, Assmann A, Schmierer P, et al. Epistatic interaction of genetic depression risk variants in the human subgenual cingulate cortex during memory encoding. Transl Psychiatry 2014;4:e372.

61. Szczepankiewicz A, Leszczynska-Rodziewicz A, Pawlak J, et al. Epistatic interaction between CRHR1 and AVPR1b variants as a predictor of major depressive disorder. Psychiatr Genet 2013;23(6):239-246.

62. Maciukiewicz M, Dmitrzak-Weglarz M, Pawlak J, et al. Analysis of genetic association and epistasis interactions between circadian clock genes and symptom dimensions of bipolar affective disorder. Chronobiol Int 2014;31(6):770-778.

63. Nicodemus KK, Hargreaves A, Morris D, et al. Variability in working memory performance explained by epistasis vs polygenic scores in the ZNF804A pathway. JAMA Psychiat 2014;71(7): 778-785.

64. Chiesa A, Lia L, Lia C, et al. Investigation of possible epistatic interactions between GRIA2 and GRIA4 variants on clinical outcomes in patients with major depressive disorder. J Int Med Res 2013;41(3):809-815.

65. Werling DM, Geschwind DH. Sex differences in autism spectrum disorders. Curr Opin Neurol 2013;26(2):146-153.

66. Werling DM, Geschwind DH. Recurrence rates provide evidence for sex-differential, familial genetic liability for autism spectrum disorders in multiplex families and twins. Mol Autism 2015;6:27.

67. Jacquemont $\mathrm{S}$, Coe BP, Hersch M, et al. A higher mutational burden in females supports a "female protective model" in neurodevelopmental disorders. Am J Hum Genet 2014;94:415425.

68. Gockley J, Willsey AJ, Dong S, Dougherty JD, Constantino JN, Sanders SJ. The female protective effect in autism spectrum disorder is not mediated by a single genetic locus. Mol Autism 2015;6:25

69. Hoffman EJ, Turner KJ, Fernandez JM, et al. Estrogens suppress a behavioral phenotype in zebrafish mutants of the autism risk gene, CNTNAP2. Neuron 2016;89(4):725-733.

70. Bao AM, Swaab DF. Sexual differentiation of the human brain: relation to gender identity, sexual orientation and neuropsychiatric disorders. Front Neuroendocrinol 2011;32:214-226.

71. Mazina V, Gerdts J, Trinh S, et al. Epigenetics of autism-related impairment: copy number variation and maternal infection. J Dev Behav Pediatr 2015;36(2):61-67.

72. Mandy W, Lai MC. Annual Research Review: The role of the environment in the developmental psychopathology of autism spectrum condition. J Child Psychol Psychiatry 2016;57(3):271-292.

73. Klengel T, Binder EB. Gene-environment interactions in major depressive disorder. Can J Psychiatry 2013;58(2):76-83.

74. Ayhan Y, McFarland R, Pletnikov MV. Animal models of geneenvironment interaction in schizophrenia: a dimensional perspective. Prog Neurobiol 2016;136:1-27. 
75. European Network of National Networks studying GeneEnvironment Interactions in Schizophrenia (EU-GEI), van Os J, Rutten BP, et al. Identifying gene-environment interactions in schizophrenia: contemporary challenges for integrated, largescale investigations. Schizophr Bull 2014;40(4):729-736.

76. Voisey J, Young RM, Lawford BR, Morris CP. Progress towards understanding the genetics of posttraumatic stress disorder. J Anxiety Disord 2014;28(8):873-883.

77. Smoller JW. The genetics of stress-related disorders: PTSD, depression, and anxiety disorders. Neuropsychopharmacology 2016;41(1):297-319.

78. McKenzie K, Milton M, Smith G, Ouellette-Kuntz H. Systematic review of the prevalence and incidence of intellectual disabilities: current trends and issues. Curr Dev Disord Rep 2016;3(2):104-115.

79. Einfeld SL, Ellis LA, Emerson E. Comorbidity of intellectual disability and mental disorder in children and adolescents: a systematic review. J Intellect Develop Disabil 2011;36(2):137-143.

80. Morgan VA, Leonard H, Bourke J, Jablensky A. Intellectual disability co-occurring with schizophrenia and other psychiatric illness: population-based study. Br J Psychiatry 2008;193(5):364-372.

81. Faraone SV, Ghirardi L, Kuja-Halkola R, Lichtenstein P, Larsson $\mathrm{H}$. The familial co-aggregation of attention-deficit/hyperactivity disorder and intellectual disability: a register-based family study. J Am Acad Child Adolesc Psychiatry 2017;56(2):167-174 e1.

82. Reichenberg A, Cederlof M, McMillan A, et al. Discontinuity in the genetic and environmental causes of the intellectual disability spectrum. Proc Natl Acad Sci U S A 2016;113(4):1098-1103.

83. Plomin R. Genetics and general cognitive ability. Nature 1999;402(6761 Suppl.):C25-C29.

84. Nevado J, Mergener R, Palomares-Bralo M, et al. New microdeletion and microduplication syndromes: a comprehensive review. Genet Mol Biol 2014;37(1 Suppl.):210-219.

85. Gilissen C, Hehir-Kwa JY, Thung DT, et al. Genome sequencing identifies major causes of severe intellectual disability. Nature 2014;511(7509):344-347.

86. Reuter MS, Tawamie H, Buchert R, et al. Diagnostic yield and novel candidate genes by exome sequencing in 152 consanguineous families with neurodevelopmental disorders. JAMA Psychiatry 2017;74:293-299.

87. Lelieveld SH, Reijnders MR, Pfundt R, et al. Meta-analysis of 2, 104 trios provides support for 10 new genes for intellectual disability. Nat Neurosci 2016;19(9):1194-1196.

88. Stessman HA, Bernier R, Eichler EE. A genotype-first approach to defining the subtypes of a complex disease. Cell 2014;156(5): 872-877.

89. Stessman HA, Willemsen MH, Fenckova M, et al. Disruption of POGZ is associated with intellectual disability and autism spectrum disorders. Am J Hum Genet 2016;98:541-552.

90. Bronicki LM, Redin C, Drunat S, et al. Ten new cases further delineate the syndromic intellectual disability phenotype caused by mutations in DYRK1A. Eur J Hum Genet 2015;23(11):1482-1487.

91. Bhoj EJ, Li D, Harr M, et al. Mutations in TBCK, encoding TBC1-domain-containing kinase, lead to a recognizable syndrome of intellectual disability and hypotonia. Am J Hum Genet 2016;98(4):782-788.

92. Harms FL, Girisha KM, Hardigan AA, et al. Mutations in EBF3 disturb transcriptional profiles and cause intellectual disability, ataxia, and facial dysmorphism. Am J Hum Genet 2017;100(1): 117-127.

93. Hempel M, Cremer K, Ockeloen CW, et al. De novo mutations in CHAMP1 cause intellectual disability with severe speech impairment. Am J Hum Genet 2015;97(3):493-500.

94. Kopajtich R, Murayama K, Janecke AR, et al. Biallelic IARS mutations cause growth retardation with prenatal onset, intellectual disability, muscular hypotonia, and infantile hepatopathy. Am J Hum Genet 2016;99(2):414-422.
95. van Karnebeek CD, Stockler S. Treatable inborn errors of metabolism causing intellectual disability: a systematic literature review. Mol Genet Metab 2012;105(3):368-381.

96. Picker JD, Walsh CA. New innovations: therapeutic opportunities for intellectual disabilities. Ann Neurol 2013;74(3):382-390.

97. Al Hafid N, Christodoulou J. Phenylketonuria: a review of current and future treatments. Transl Pediatr 2015;4(4):304-317.

98. van de Kamp JM, Mancini GM, Salomons GS. X-linked creatine transporter deficiency: clinical aspects and pathophysiology. J Inherit Metab Dis 2014;37(5):715-733.

99. Burrage LC, Nagamani SC, Campeau PM, Lee BH. Branchedchain amino acid metabolism: from rare Mendelian diseases to more common disorders. Hum Mol Genet 2014;23(R1):R1-R8.

100. Novarino G, El-Fishawy P, Kayserili H, et al. Mutations in BCKD-kinase lead to a potentially treatable form of autism with epilepsy. Science 2012;338(6105):394-397.

101. Scott K, Gadomski T, Kozicz T, Morava E. Congenital disorders of glycosylation: new defects and still counting. J Inherit Metab Dis 2014;37(4):609-617.

102. Platt FM, Boland B, van der Spoel AC. The cell biology of disease: lysosomal storage disorders: the cellular impact of lysosomal dysfunction. J Cell Biol 2012;199(5):723-734.

103. Kochinke K, Zweier C, Nijhof B, et al. Systematic phenomics analysis deconvolutes genes mutated in intellectual disability into biologically coherent modules. Am J Hum Genet 2016;98(1):149-164.

104. Verpelli C, Galimberti I, Gomez-Mancilla B, Sala C. Molecular basis for prospective pharmacological treatment strategies in intellectual disability syndromes. Dev Neurobiol 2014;74(2):197-206.

105. Matson JL, Bamburg JW, Mayville EA, et al. Psychopharmacology and mental retardation: a 10 year review (1990-1999). Res Dev Disabil 2000;21:263-296.

106. Matson JL, Bielecki J, Mayville SB, Matson ML. Psychopharmacology research for individuals with mental retardation: methodological issues and suggestions. Res Dev Disabil 2003;24(3):149-157.

107. Matson JL, Mahan S. Antipsychotic drug side effects for persons with intellectual disability. Res Dev Disabil 2010;31(6):1570-1576.

108. Jacquemont S, Curie A, des Portes V, et al. Epigenetic modification of the FMR 1 gene in fragile $\mathrm{X}$ syndrome is associated with differential response to the mGluR5 antagonist AFQ056. Sci Transl Med 2011;3(64):64ra1.

109. Berry-Kravis E, Des Portes V, Hagerman R, et al. Mavoglurant in fragile X syndrome: Results of two randomized, double-blind, placebo-controlled trials. Sci Transl Med 2016;8(321):321ra5.

110. Gantois I, Pop AS, de Esch CE, et al. Chronic administration of AFQ056/Mavoglurant restores social behaviour in Fmr1 knockout mice. Behav Brain Res 2013;239:72-79.

111. Pop AS, Levenga J, de Esch CE, et al. Rescue of dendritic spine phenotype in Fmr1 KO mice with the mGluR5 antagonist AFQ056/ Mavoglurant. Psychopharmacology 2014;231:1227-1235.

112. Seese RR, Maske AR, Lynch G, Gall CM. Long-term memory deficits are associated with elevated synaptic ERK1/2 activation and reversed by mGluR5 antagonism in an animal model of autism. Neuropsychopharmacology 2014;39(7):1664-1673.

113. Berry-Kravis E, Krause SE, Block SS, et al. Effect of CX516, an AMPA-modulating compound, on cognition and behavior in fragile X syndrome: a controlled trial. J Child Adolesc Psychopharmacol 2006;16(5):525-540..

114. Goff DC, Lamberti JS, Leon AC, et al. A placebo-controlled addon trial of the Ampakine, CX516, for cognitive deficits in schizophrenia. Neuropsychopharmacology 2008;33(3):465-472.

115. Berry-Kravis EM, Hessl D, Rathmell B, et al. Effects of STX209 (arbaclofen) on neurobehavioral function in children and adults with fragile $\mathrm{X}$ syndrome: a randomized, controlled, phase 2 trial. Sci Transl Med 2012;4(152):152ra27. 
116. Troca-Marin JA, Alves-Sampaio A, Montesinos ML. Deregulated mTOR-mediated translation in intellectual disability. Prog Neurobiol 2012;96(2):268-282.

117. Troca-Marin JA, Casanas JJ, Benito I, Montesinos ML. The AktmTOR pathway in Down's syndrome: the potential use of rapamycin/rapalogs for treating cognitive deficits. CNS Neurol Disord Drug Targets 2014;13(1):34-40.

118. Sandin S, Lichtenstein P, Kuja-Halkola R, Larsson H, Hultman $\mathrm{CM}$, Reichenberg A. The familial risk of autism. JAMA 2014;311(17):1770-1777.

119. Christensen DL, Bilder DA, Zahorodny W, et al. Prevalence and characteristics of autism spectrum disorder among 4-year-old children in the autism and developmental disabilities monitoring network. J Dev Behav Pediatr 2016;37(1):1-8

120. He X, Sanders SJ, Liu L, et al. Integrated model of de novo and inherited genetic variants yields greater power to identify risk genes. PLOS Genet 2013;9(8):e1003671.

121. Liu L, Lei J, Sanders SJ, et al. DAWN: a framework to identify autism genes and subnetworks using gene expression and genetics. Mol Autism 2014;5(1):22.

122. Michaelson JJ, Sebat J. forestSV: structural variant discovery through statistical learning. Nat Methods 2012;9(8):819-821.

123. Robinson EB, St Pourcain B, Anttila V, et al. Genetic risk for autism spectrum disorders and neuropsychiatric variation in the general population. Nat Genet 2016;48(5):552-555.

124. Weiss LA, Shen Y, Korn JM, et al. Association between microdeletion and microduplication at $16 \mathrm{p} 11.2$ and autism. N Engl J Med 2008;358(7):667-675.

125. Jiang YH, Yuen RK, Jin X, et al. Detection of clinically relevant genetic variants in autism spectrum disorder by whole-genome sequencing. Am J Hum Genet 2013;93(2):249-263.

126. O'Roak BJ, Vives $\mathrm{L}, \mathrm{Fu}$ W, et al. Multiplex targeted sequencing identifies recurrently mutated genes in autism spectrum disorders. Science 2012;338(6114):1619-1622.

127. Helsmoortel C, Vulto-van Silfhout AT, Coe BP, et al. A SWI/SNFrelated autism syndrome caused by de novo mutations in ADNP. Nat Genet 2014;46:380-384.

128. Reissner C, Runkel F, Missler M. Neurexins. Genome Biol 2013;14(9):213.

129. Krueger DD, Tuffy LP, Papadopoulos T, Brose N. The role of neurexins and neuroligins in the formation, maturation, and function of vertebrate synapses. Curr Opin Neurobiol 2012;22(3):412-422.

130. Guilmatre A, Huguet G, Delorme R, Bourgeron T. The emerging role of SHANK genes in neuropsychiatric disorders. Develop Neurobiol 2014;74(2):113-122.

131. Zuko A, Kleijer KT, Oguro-Ando A, et al. Contactins in the neurobiology of autism. Eur J Pharmacol 2013;719(1-3):63-74.

132. Blumenthal I, Ragavendran A, Erdin S, et al. Transcriptional consequences of $16 \mathrm{p} 11.2$ deletion and duplication in mouse cortex and multiplex autism families. Am J Hum Genet 2014;94(6): 870-883.

133. Krumm N, Turner TN, Baker C, et al. Excess of rare, inherited truncating mutations in autism. Nat Genet 2015;47(6):582-588.

134. Deriziotis P, O'Roak BJ, Graham SA, et al. De novo TBR1 mutations in sporadic autism disrupt protein functions. Nat Commun 2014;5:4954

135. Sweatt JD. Pitt-Hopkins Syndrome: intellectual disability due to loss of TCF4-regulated gene transcription. Exp Mol Med 2013;45:e21.

136. Michalon A, Sidorov M, Ballard TM, et al. Chronic pharmacological mGlu5 inhibition corrects fragile $\mathrm{X}$ in adult mice. Neuron 2012;74(1):49-56

137. Chapleau CA, Lane J, Pozzo-Miller L, Percy AK. Evaluation of current pharmacological treatment options in the management of Rett syndrome: from the present to future therapeutic alternatives. Curr Clin Pharmacol 2013;8(4):358-369.
138. Buchovecky CM, Turley SD, Brown HM, et al. A suppressor screen in Mecp2 mutant mice implicates cholesterol metabolism in Rett syndrome. Nat Genet 2013;45(9):1013-1020.

139. Sztainberg Y, Chen HM, Swann JW, et al. Reversal of phenotypes in MECP2 duplication mice using genetic rescue or antisense oligonucleotides. Nature 2015;528(7580):123-126.

140. Shcheglovitov A, Shcheglovitova O, Yazawa M, et al. SHANK3 and IGF1 restore synaptic deficits in neurons from 22q13 deletion syndrome patients. Nature 2013;503(7475):267-271.

141. Han S, Tai C, Westenbroek RE, et al. Autistic-like behaviour in Scn1a+/- mice and rescue by enhanced GABA-mediated neurotransmission. Nature 2012;489(7416):385-390.

142. Tsai PT, Hull C, Chu Y, et al. Autistic-like behaviour and cerebellar dysfunction in Purkinje cell Tsc1 mutant mice. Nature 2012;488(7413):647-651.

143. Tian D, Stoppel LJ, Heynen AJ, et al. Contribution of mGluR5 to pathophysiology in a mouse model of human chromosome 16p11.2 microdeletion. Nat Neurosci 2015;18(2):182-184.

144. Ghirardi L, Brikell I, Kuja-Halkola R, et al. The familial coaggregation of ASD and ADHD: a register-based cohort study. Mol Psychiatry 2017 Feb 28.

145. Polanczyk G, de Lima MS, Horta BL, Biederman J, Rohde LA. The worldwide prevalence of ADHD: a systematic review and metaregression analysis. Am J Psychiatry 2007;164(6):942-948.

146. Willcutt EG. The prevalence of DSM-IV attention-deficit/hyperactivity disorder: a meta-analytic review. Neurotherapeutics 2012;9(3):490-499.

147. Simon V, Czobor P, Balint S, Meszaros A, Bitter I. Prevalence and correlates of adult attention-deficit hyperactivity disorder: metaanalysis. Br J Psychiatry 2009;194(3):204-211.

148. Franke B, Faraone SV, Asherson P, et al. The genetics of attention deficit/hyperactivity disorder in adults, a review. Mol Psychiatry 2012;17(10):960-987.

149. Burt SA. Rethinking environmental contributions to child and adolescent psychopathology: a meta-analysis of shared environmental influences. Psychol Bull 2009;135:608-637.

150. Faraone SV, Perlis RH, Doyle AE, et al. Molecular genetics of attention-deficit/hyperactivity disorder. Biol Psychiatry 2005;57: $1313-1323$.

151. Li Z, Chang SH, Zhang LY, Gao L, Wang J. Molecular genetic studies of ADHD and its candidate genes: a review. Psychiatry Res 2014;219(1):10-24

152. Akutagava-Martins GC, Rohde LA, Hutz MH. Genetics of attention-deficit/hyperactivity disorder: an update. Exp Rev Neurother 2016;16:145-156.

153. Hawi Z, Cummins TD, Tong J, et al. The molecular genetic architecture of attention deficit hyperactivity disorder. Mol Psychiatry 2015;20(3):289-297.

154. Bralten J, Franke B, Waldman I, et al. Candidate genetic pathways for attention-deficit/hyperactivity disorder (ADHD) show association to hyperactive/impulsive symptoms in children with ADHD. J Am Acad Child Adolesc Psychiatry 2013;52(11):1204-1212 e1.

155. Poelmans G, Pauls DL, Buitelaar JK, Franke B. Integrated genome-wide association study findings: identification of a neurodevelopmental network for attention deficit hyperactivity disorder. Am J Psychiatry 2011;168(4):365-377.

156. Elia J, Glessner JT, Wang K, et al. Genome-wide copy number variation study associates metabotropic glutamate receptor gene networks with attention deficit hyperactivity disorder. Nat Genet 2011;44:78-84.

157. Akutagava-Martins GC, Salatino-Oliveira A, Genro JP, et al. Glutamatergic copy number variants and their role in attentiondeficit/hyperactivity disorder. Am J Med Genet Part B Neuropsychiatr Genet 2014;165B(6):502-509. 
158. Maltezos S, Horder J, Coghlan S, et al. Glutamate/glutamine and neuronal integrity in adults with ADHD: a proton MRS study. Transl Psychiatry 2014;4:e373.

159. Hadley D, Wu ZL, Kao C, et al. The impact of the metabotropic glutamate receptor and other gene family interaction networks on autism. Nat Commun 2014;5:4074.

160. Naaijen J, Bralten J, Poelmans G, et al. Glutamatergic and GABAergic gene sets in attention-deficit/hyperactivity disorder: association to overlapping traits in ADHD and autism. Transl Psychiatry 2017;7(1):e999.

161. Cheng J, Xiong Z, Duffney LJ, et al. Methylphenidate exerts dosedependent effects on glutamate receptors and behaviors. Biol Psychiatry 2014;76(12):953-962.

162. Park S, Kim BN, Cho SC, et al. The metabotropic glutamate receptor subtype 7 rs3792452 polymorphism is associated with the response to methylphenidate in children with attention-deficit/hyperactivity disorder. J Child Adolesc Psychopharmacol 2014;24(4):223-227.

163. O'Sullivan ML, Martini F, von Daake S, Comoletti D, Ghosh A. LPHN3, a presynaptic adhesion-GPCR implicated in ADHD, regulates the strength of neocortical layer $2 / 3$ synaptic input to layer 5. Neural Dev 2014;9:7.

164. Arcos-Burgos M, Jain M, Acosta MT, et al. A common variant of the latrophilin 3 gene, LPHN3, confers susceptibility to ADHD and predicts effectiveness of stimulant medication. Mol Psychiatry 2010;15(11):1053-1066

165. Arcos-Burgos M, Velez JI, Solomon BD, Muenke M. A common genetic network underlies substance use disorders and disruptive or externalizing disorders. Hum Genet 2012;131(6):917-929.

166. Ribases M, Ramos-Quiroga JA, Sanchez-Mora C, et al. Contribution of LPHN3 to the genetic susceptibility to ADHD in adulthood: a replication study. Genes Brain Behav 2011;10(2):149-157.

167. Fallgatter AJ, Ehlis AC, Dresler T, et al. Influence of a latrophilin 3 (LPHN3) risk haplotype on event-related potential measures of cognitive response control in attention-deficit hyperactivity disorder (ADHD). Eur Neuropsychopharmacol 2013;23(6):458-468.

168. Acosta MT, Velez JI, Bustamante ML, Balog JZ, Arcos-Burgos M, Muenke M. A two-locus genetic interaction between LPHN3 and 11q predicts ADHD severity and long-term outcome. Transl Psychiatry 2011;1:e17.

169. Jain M, Velez JI, Acosta MT, et al. A cooperative interaction between LPHN3 and 11q doubles the risk for ADHD. Mol Psychiatry 2012;17(7):741-747.

170. Choudhry Z, Sengupta SM, Grizenko N, et al. LPHN3 and attention-deficit/hyperactivity disorder: interaction with maternal stress during pregnancy. J Child Psychol Psychiatry 2012;53(8):892-902.

171. Labbe A, Liu A, Atherton J, et al. Refining psychiatric phenotypes for response to treatment: contribution of LPHN3 in ADHD. Am J Med Genet Part B Neuropsychiatr Genet 2012;159B(7):776-785.

172. Hwang IW, Lim MH, Kwon HJ, Jin HJ. Association of LPHN3 rs6551665 A/G polymorphism with attention deficit and hyperactivity disorder in Korean children. Gene 2015;566(1):68-73.

173. Bruxel EM, Salatino-Oliveira A, Akutagava-Martins GC, et al. LPHN3 and attention-deficit/hyperactivity disorder: a susceptibility and pharmacogenetic study. Genes Brain Behav 2015;14(5): 419-427.

174. Song J, Kim SW, Hong HJ, et al. Association of SNAP-25, SLC6A2, and LPHN3 with OROS methylphenidate treatment response in attention-deficit/hyperactivity disorder. Clin Neuropharmacol 2014;37(5):136-141.

175. Martinez AF, Abe Y, Hong S, et al. An ultraconserved brainspecific enhancer within ADGRL3 (LPHN3) underpins attention-deficit/hyperactivity disorder susceptibility. Biol Psychiatry 2016;80(12):943-954.
176. O'Sullivan ML, de Wit J, Savas JN, et al. FLRT proteins are endogenous latrophilin ligands and regulate excitatory synapse development. Neuron 2012;73(5):903-910.

177. Lu YC, Nazarko OV, Sando R, 3rd, Salzman GS, Sudhof TC, Arac D. Structural basis of latrophilin-FLRT-UNC5 interaction in cell adhesion. Structure 2015;23:1678-1691.

178. Lesch KP, Merker S, Reif A, Novak M. Dances with black widow spiders: dysregulation of glutamate signalling enters centre stage in ADHD. Eur Neuropsychopharmacol 2013;23(6):479-491.

179. Elia J, Gai X, Xie HM, et al. Rare structural variants found in attention-deficit hyperactivity disorder are preferentially associated with neurodevelopmental genes. Mol Psychiatry 2010;15(6): 637-646.

180. Lionel AC, Crosbie J, Barbosa N, et al. Rare copy number variation discovery and cross-disorder comparisons identify risk genes for ADHD. Sci Transl Med 2011;3(95):95ra75.

181. Williams NM, Zaharieva I, Martin A, et al. Rare chromosomal deletions and duplications in attention-deficit hyperactivity disorder: a genome-wide analysis. Lancet 2010;376(9750): 1401-1408.

182. Lesch KP, Timmesfeld N, Renner TJ, et al. Molecular genetics of adult ADHD: converging evidence from genome-wide association and extended pedigree linkage studies. J Neural Transm (Vienna) 2008;115(11):1573-1585.

183. Zayats T, Jacobsen KK, Kleppe R, et al. Exome chip analyses in adult attention deficit hyperactivity disorder. Transl Psychiatry 2016;6(10):e923.

184. Demontis D, Lescai F, Borglum A, et al. Whole-exome sequencing reveals increased burden of rare functional and disruptive variants in candidate risk genes in individuals with persistent attention-deficit/hyperactivity disorder. J Am Acad Child Adolesc Psychiatry 2016;55(6):521-523.

185. Tomblin JB, Records NL, Buckwalter P, Zhang X, Smith E, O'Brien M. Prevalence of specific language impairment in kindergarten children. J Speech Lang Hear Res 1997;40:1245-1260.

186. Lewis BA, Thompson LA. A study of developmental speech and language disorders in twins. J Speech Hear Res 1992;35(5):10861094.

187. Bishop DV, North T, Donlan C. Genetic basis of specific language impairment: evidence from a twin study. Develop Med Child Neurol 1995;37(1):56-71.

188. Tomblin JB, Buckwalter PR. Heritability of poor language achievement among twins. J Speech Lang Hear Res 1998;41(1): 188-199.

189. Dale PS, Simonoff E, Bishop DV, et al. Genetic influence on language delay in two-year-old children. Nat Neurosci 1998;1(4):324-328.

190. Tomblin JB, Mueller KL. How Can the comorbidity with ADHD aid understanding of language and speech disorders? Top Lang Disord 2012;32(3):198-206.

191. Lai CS, Fisher SE, Hurst JA, Vargha-Khadem F, Monaco AP. A forkhead-domain gene is mutated in a severe speech and language disorder. Nature 2001;413(6855):519-523.

192. MacDermot KD, Bonora E, Sykes N, et al. Identification of FOXP2 truncation as a novel cause of developmental speech and language deficits. Am J Hum Genet 2005;76(6):1074-1080.

193. Shriberg LD, Ballard KJ, Tomblin JB, Duffy JR, Odell KH, Williams CA. Speech, prosody, and voice characteristics of a mother and daughter with a 7;13 translocation affecting FOXP2. J Speech Lang Hear Res 2006;49(3):500-525.

194. Feuk L, Kalervo A, Lipsanen-Nyman M, et al. Absence of a paternally inherited FOXP2 gene in developmental verbal dyspraxia. Am J Hum Genet 2006;79(5):965-972.

195. Mueller KL, Murray JC, Michaelson JJ, Christiansen MH, Reilly $\mathrm{S}$, Tomblin JB. Common genetic variants in FOXP2 are not 
associated with individual differences in language development. PLOS ONE 2016;11(4):e0152576.

196. Newbury DF, Bonora E, Lamb JA, et al. FOXP2 is not a major susceptibility gene for autism or specific language impairment. Am J Hum Genet 2002;70(5):1318-1327.

197. Gialluisi A, Newbury DF, Wilcutt EG, et al. Genome-wide screening for DNA variants associated with reading and language traits. Genes Brain Behav 2014;13(7):686-701.

198. Simpson NH, Ceroni F, Reader RH, et al. Genome-wide analysis identifies a role for common copy number variants in specific language impairment. Eur J Hum Genet 2015;23(10):1370-1377.

199. Kornilov SA, Rakhlin N, Koposov R, et al. Genome-wide association and exome sequencing study of language disorder in an isolated population. Pediatrics 2016;137(4):e20152469.

200. Villanueva P, Nudel R, Hoischen A, et al. Exome sequencing in an admixed isolated population indicates NFXL1 variants confer a risk for specific language impairment. PLOS Genet 2015;11(3): e1004925.

201. Paschou P, Fernandez TV, Sharp F, Heiman GA, Hoekstra PJ. Genetic susceptibility and neurotransmitters in Tourette syndrome. Int Rev Neurobiol 2013;112:155-177.

202. Comings DE, Comings BG, Devor EJ, Cloninger CR. Detection of major gene for Gilles de la Tourette syndrome. Am J Hum Genet 1984;36(3):586-600.

203. Pauls DL, Leckman JF. The inheritance of Gilles de la Tourette's syndrome and associated behaviors. Evidence for autosomal dominant transmission. N Engl J Med 1986;315(16):993-997.

204. Walkup JT, LaBuda MC, Singer HS, Brown J, Riddle MA, Hurko O. Family study and segregation analysis of Tourette syndrome: evidence for a mixed model of inheritance. Am J Hum Genet 1996;59(3):684-693.

205. State MW. The genetics of Tourette disorder. Curr Opin Genet Dev 2011;21:302-309.

206. Hirschtritt ME, Lee PC, Pauls DL, et al. Lifetime prevalence, age of risk, and genetic relationships of comorbid psychiatric disorders in Tourette syndrome. JAMA Psychiat 2015;72(4):325-333.

207. Ercan-Sencicek AG, Stillman AA, Ghosh AK, et al. L-histidine decarboxylase and Tourette's syndrome. N Engl J Med 2010;362(20):1901-1908

208. Fernandez TV, Sanders SJ, Yurkiewicz IR, et al. Rare copy number variants in tourette syndrome disrupt genes in histaminergic pathways and overlap with autism. Biol Psychiatry 2012;71(5): 392-402.

209. Karagiannidis I, Dehning S, Sandor P, et al. Support of the histaminergic hypothesis in Tourette syndrome: association of the histamine decarboxylase gene in a large sample of families. J Med Genet 2013;50(11):760-764

210. Castellan Baldan L, Williams KA, Gallezot JD, et al. Histidine decarboxylase deficiency causes tourette syndrome: parallel findings in humans and mice. Neuron 2014;81(1):77-90.

211. Scharf JM, Yu D, Mathews CA, et al. Genome-wide association study of Tourette's syndrome. Mol Psychiatry 2013;18(6):721-728.

212. Paschou P, Yu D, Gerber G, et al. Genetic association signal near NTN4 in Tourette syndrome. Ann Neurol 2014;76(2):310-315.

213. Padmanabhuni SS, Houssari R, Esserlind AL, et al. Investigation of SNP rs2060546 Immediately upstream to NTN4 in a Danish Gilles de la Tourette syndrome cohort. Front Neurosci 2016;10:531.

214. Zilhao NR, Padmanabhuni SS, Pagliaroli L, et al. Epigenomewide association study of tic disorders. Twin Res Hum Genet 2015;18(6):699-709.

215. Abdulkadir M, Tischfield JA, King RA, et al. Pre- and perinatal complications in relation to Tourette syndrome and co-occurring obsessive-compulsive disorder and attention-deficit/hyperactivity disorder. J Psychiatr Res 2016;82:126-135.

216. Dietrich A, Fernandez TV, King RA, et al. The Tourette International Collaborative Genetics (TIC Genetics) study, finding the genes causing Tourette syndrome: objectives and methods. Eur Child Adolesc Psychiatry 2015;24(2):141-151.

217. Regier DA, Narrow WE, Rae DS, Manderscheid RW, Locke BZ, Goodwin FK. The de facto US mental and addictive disorders service system. Epidemiologic catchment area prospective 1-year prevalence rates of disorders and services. Arch Gen Psychiatry 1993;50:85-94.

218. Sullivan PF, Kendler KS, Neale MC. Schizophrenia as a complex trait: evidence from a meta-analysis of twin studies. Arch Gen Psychiatry 2003;60(12):1187-1192.

219. Lichtenstein P, Yip BH, Bjork C, et al. Common genetic determinants of schizophrenia and bipolar disorder in Swedish families: a population-based study. Lancet 2009;373(9659):234-239.

220. Buckley PF, Miller BJ, Lehrer DS, Castle DJ. Psychiatric comorbidities and schizophrenia. Schizophr Bull 2009;35(2):383-402.

221. Rees E, O'Donovan MC, Owen MJ. Genetics of schizophrenia. Curr Opin Behav Sci 2015;2:8-14.

222. Purcell SM, Moran JL, Fromer M, et al. A polygenic burden of rare disruptive mutations in schizophrenia. Nature 2014;506(7487):185-190.

223. Neale BM, Sklar P. Genetic analysis of schizophrenia and bipolar disorder reveals polygenicity but also suggests new directions for molecular interrogation. Curr Opin Neurobiol 2015;30:131-138.

224. Schizophrenia Working Group of the Psychiatric Genomics Consortium. Biological insights from 108 schizophreniaassociated genetic loci. Nature 2014;511(7510):421-427.

225. Sekar A, Bialas AR, de Rivera H, et al. Schizophrenia risk from complex variation of complement component 4. Nature 2016;530(7589):177-183.

226. Dhindsa RS, Goldstein DB. Schizophrenia: from genetics to physiology at last. Nature 2016;530(7589):162-163.

227. Hall J, Trent S, Thomas KL, O'Donovan MC, Owen MJ. Genetic risk for schizophrenia: convergence on synaptic pathways involved in plasticity. Biol Psychiatry 2015;77(1):52-58.

228. Kessler RC, Chiu WT, Demler O, Merikangas KR, Walters EE. Prevalence, severity, and comorbidity of 12-month DSM-IV disorders in the National Comorbidity Survey Replication. Arch Gen Psychiatry 2005;62(6):617-627.

229. Barnett JH, Smoller JW. The genetics of bipolar disorder Neuroscience 2009;164(1):331-343.

230. Crump C, Sundquist K, Winkleby MA, Sundquist J. Comorbidities and mortality in bipolar disorder: a Swedish national cohort study. JAMA Psychiat 2013;70(9):931-939.

231. Hou L, Bergen SE, Akula N, et al. Genome-wide association study of 40,000 individuals identifies two novel loci associated with bipolar disorder. Hum Mol Genet 2016;25:33833394.

232. Goes FS, Pirooznia M, Parla JS, et al. Exome sequencing of familial bipolar disorder. JAMA Psychiat 2016;73(6):590-597.

233. Demyttenaere K, Bruffaerts R, Posada-Villa J, et al. Prevalence, severity, and unmet need for treatment of mental disorders in the World Health Organization World Mental Health Surveys. JAMA 2004;291(21):2581-2590.

234. Kessler RC, Berglund P, Demler O, et al. The epidemiology of major depressive disorder: results from the National Comorbidity Survey Replication (NCS-R). JAMA 2003;289(23):3095-3105.

235. Thaipisuttikul P, Ittasakul P, Waleeprakhon P, Wisajun P, Jullagate S. Psychiatric comorbidities in patients with major depressive disorder. Neuropsychiatr Dis Treat 2014;10:2097-2103.

236. Kendler KS, Gatz M, Gardner CO, Pedersen NL. A Swedish national twin study of lifetime major depression. Am J Psychiatry 2006;163(1):109-114. 
237. Sullivan PF, Neale MC, Kendler KS. Genetic epidemiology of major depression: review and meta-analysis. Am J Psychiatry 2000;157(10):1552-1562.

238. Flint J, Kendler KS. The genetics of major depression. Neuron 2014;81(3):484-503.

239. Hyde CL, Nagle MW, Tian C, et al. Identification of 15 genetic loci associated with risk of major depression in individuals of European descent. Nat Genet 2016;48(9):1031-1036.

240. CONVERGE Consortium. Sparse whole-genome sequencing identifies two loci for major depressive disorder. Nature 2015;523(7562):588-591.
241. Jansen R, Penninx BW, Madar V, et al. Gene expression in major depressive disorder. Mol Psychiatry 2016;21(3):339-347.

242. Major Depressive Disorder Working Group of the Psychiatric GWAS Consortium, Ripke S, Wray NR, et al. A mega-analysis of genome-wide association studies for major depressive disorder. Mol Psychiatry 2013;18(4):497-511.

243. Kappelmann N, Lewis G, Dantzer R, Jones PB, Khandaker GM. Antidepressant activity of anti-cytokine treatment: a systematic review and meta-analysis of clinical trials of chronic inflammatory conditions. Mol Psychiatry 2016 Oct 18 . 